\title{
Effects of breeding season and mating on total number and distribution of spermatozoa in the epididymis of the brown marsupial mouse, Antechinus stuartii
}

\author{
D. A. Taggart and P. D. Temple-Smith \\ Department of Anatomy, Monash University, Clayton, Victoria 3168, Australia
}

\begin{abstract}
Summary. Changes in the number and distribution of spermatozoa in the epididymis of the adult brown marsupial mouse were examined during July/August in mated and unmated males. The effects of mating on epididymal sperm populations were studied in 2 groups of males each mated 3 times and compared with the number and distribution of spermatozoa in the epididymides of 4 unmated control groups. One testis and epididymis were removed from each animal (hemicastration) either before or early in the mating season to provide information on initial sperm content and distribution. The contralateral side was removed later in the mating season to examine the effects of mating or sexual abstinence on epididymal sperm distribution.

Epididymal sperm number peaked in both the distal caput and distal corpus/proximal cauda epididymidis in late July. The total number of spermatozoa, including those remaining in the testis, available to each male at the beginning of the mating season in early August was $\sim 4.4 \times 10^{6} /$ side. Although recruitment of spermatozoa into the epididymis from the testis continued until mid-August, sperm content of the epididymis reached a peak of about $3.5 \times 10^{6}$ epididymis in early August. At this time approximately $0.9 \times 10^{6}$ spermatozoa remained in the testis which had ceased spermatogenic activity. Throughout the mating season, epididymal spermatozoa were concentrated in the distal corpus/proximal cauda regions of the epididymis and were replenished by spermatozoa from upper regions of the duct. Relatively few spermatozoa were found in the distal cauda epididymidis, confirming a low sperm storage capacity in this region.

A constant loss of spermatozoa from the epididymis, probably via spermatorrhoea, occurred throughout the mating season and very few spermatozoa remained in unmated males in late August before the annual male die-off. Mating studies showed that an average of $0.23 \times 10^{6}$ spermatozoa/epididymis were delivered per mating in this species, but the number of spermatozoa released at each ejaculation may be as few as $0.04 \times 10^{6}$ /epididymis when sperm loss via spermatorrhoea is taken into account.

We suggest that the unusual structure of the cauda epididymidis, which has a very restricted sperm storage capacity, may function to limit the numbers of spermatozoa available at each ejaculation and thus conserve the dwindling epididymal sperm reserves in order to maximize the number of successful matings which are possible during the mating season.
\end{abstract}

Keyw'ords: epididymis; spermatozoa; sperm storage; mating; marsupial; dasyurid

\section{Introduction}

The brown marsupial mouse, which forms the basis of this study, has been a popular focus for research because of some interesting and unusual aspects in its life history and reproductive biology. For example, males are polygynous (Scott \& Tan, 1985) and participate in a lek-type promiscuity 
mating system (Lazenby-Cohen \& Cockburn, 1988). After mating, but often before the inseminated females have ovulated, there is a highly synchronized, stress-related die-off of all males in the population (Lee et al., 1977; Bradley et al., 1980; Lee \& Cockburn, 1985). In males the testis undergoes a single spermatogenic generation and the production of spermatozoa fails completely before the mating season (Woolley, 1966; Taylor \& Horner, 1970; Kerr \& Hedger, 1983). Although males are polygynous, the sperm content of the epididymis is low (Taggart \& Temple-Smith, 1989), the storage capacity of the caudal region appears to be very limited (Taggart \& Temple-Smith, 1989), and there is continuous loss of spermatozoa via spermatorrhoea in sexually mature males (Woolley, 1966).

Bedford et al. (1984) have described sparse sperm populations and limited caudal storage capacity in the epididymides of other dasyurid marsupials and also in the American didelphid and caenolestid marsupials. In contrast, other marsupial families like the Macropodoidae and Phalangeroidae display a eutherian pattern (Amann et al., 1979; Amann, 1981) of sperm distribution and content in the epididymis (Bedford et al., 1984). In the brown marsupial mouse, Antechinus stuartii, there is an unusual structural organization of the cauda epididymidis (Taggart \& Temple-Smith, 1989) which may explain the limited sperm storage capacity in this species, but further study is needed to examine the effects of mating on sperm distribution and epididymal sperm reserves.

In mammals the epididymis is considered to perform three major functions other than sperm transport. The initial segment of the epididymis is involved in the absorption of most of the fluid leaving the testis, the middle segment in completion of sperm maturation and the terminal or caudal segment is associated with the storage of mature spermatozoa before ejaculation (Glover $\&$ Nicander, 1971; Cummins, 1981). Species in which the male displays a polygynous mating system are thought to obtain the greatest advantage by maximizing the sperm storage function of the epididymis (Bedford, 1978). This seems to contrast with the situation in the brown marsupial mouse.

This paper examines the effects of mating on the total number and distribution of spermatozoa in the epididymis of brown marsupial mice and compares these results with epididymal sperm counts from unmated males throughout the mating season. From these observations we have been able to estimate the number of spermatozoa ejaculated during each mating, sperm loss due to spermatorrhoea, and the effects of spermatogenic failure in the testis on sperm distribution in the epididymis during the breeding season.

\section{Materials and Methods}

\section{Animal capture and maintenance}

Reproductive tissues were collected from 30 sexually mature adult males trapped during July/August in wet sclerophyll forest near Powelltown, 60 miles east of Melbourne in the state of Victoria. Thirty adult female brown marsupial mice were also collected and used for mating studies only, before being returned to their site of capture, along with any maies that had not undergone annual male die-off, at the end of the breeding season in early September (Conservation, Forests and Lands permit Nos 87/88 and 88/55).

After capture, animals were returned to the laboratory, housed in individual cages and fed on a diet of meal worms, honey/rolled oats, moistened puppy chow and water ad libitum for several days until required for experimentation.

\section{Animal groups}

Males were divided into 6 groups of 5 animals; 4 control groups which were unmated in captivity and 2 experimental groups which were mated a total of 3 times each at predetermined dates during the mating season (Fig. 1). Males in Groups 1 and 2 (controls) were caught and hemicastrated in late July/early August before the mating season. These groups remained unmated and the contralateral testis/epididymis was removed for assessment in late August. Males in Groups 3 and 4 (controls) were caught and hemicastrated early in the mating season and completely castrated in mid- to late August. For Group 5, males were captured in late July and hemicastrated before the mating season: each male was then allowed to mate 3 times in mid-August and the contralateral testis and epididymis were removed on about 21 August. In Group 6, males were captured and hemicastrated in mid-August (the mating season), mated 3 
times, and completely castrated on about 22 August. Animals in Groups 1, 5 and 6 were captured and studied during July/August 1987 whilst those in Groups 2, 3 and 4 were captured and studied during the 1988 season.

\section{Mating trials}

Oestrous females were used in the mating trials. Oestrus was determined by the presence of cornified epithelial cells in urine samples (Godfrey, 1969; Selwood, 1985) collected 3 times per week during August.

Males were placed in a glass-bottomed container with an oestrous female and allowed to mate. Animals were monitored throughout mating and urine samples were collected from females at the conclusion of mating. A successful mating was not recorded unless intromission was observed through the glass floor of the cage and spermatozoa were present in the urine of the female.

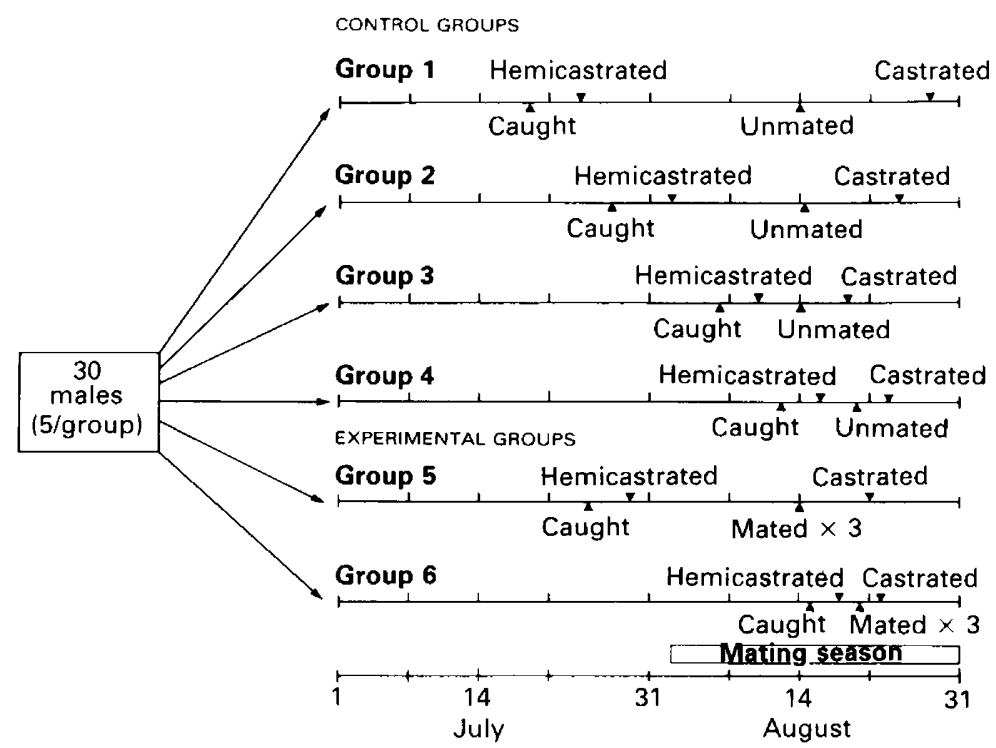

Fig. 1. Animal groups, showing approximate dates of capture, hemicastration, mating and castration throughout July/August in control (1-4) and experimental (5 \& 6) groups.

\section{Tissue preparation}

Anaesthesia was induced with Saffan containing $9 \mathrm{mg}$ alphadolone acetate and $3 \mathrm{mg}$ alphaxalone acetate $/ \mathrm{ml}$ (Glaxovet, Glaxo Australia Pty Ltd, Boronia, Victoria, Australia), $2.1 \mathrm{ml} / \mathrm{kg}$ injected intramuscularly. The spermatic cord was coagulated using microbipolar coagulation forceps attached to a Surgistat diathermy unit (Valley Laboratories, Boulder, CO, USA). Each animal was then hemicastrated and the scrotal incision repaired using $6 / 0$ nylon sutures (Ethnor Pty Ltd, Sydney, Australia) and a double layer closure technique. Testicular and epididymal tissue were weighed and placed in Dulbecco's Modified Eagles Medium (DMEM) (cat. no. 430-1600; Gibco Pty Ltd, Canada L7P IA I). Animals were then allowed to recover. Recovery from this procedure was rapid ( $<1$ day) and no adverse effects were observed on male breeding behaviour. Epididymides were cut into 12 segments (Taggart \& Temple-Smith, 1989) and each segment placed in a drop of DMEM. This procedure was repeated for the removal of the contralateral testis and epididymis.

\section{Estimation of sperm number}

Epididymis. Since marsupial spermatozoa are more fragile (Temple-Smith \& Bedford, 1976; Cummins, 1981) than those of eutherian mammals, standard homogenization methods could not be used to separate spermatozoa from testicular or epididymal tissue because of the possibility of sperm loss by mechanical or chemical disintegration.

Spermatozoa were removed from each epididymal segment by cutting the tubules and squeezing the tissue, to force the spermatozoa contained within the tubules out into the surrounding medium. The medium was then replaced and the procedure repeated until no further spermatozoa could be obtained. 
Six drops of homogenizing fluid (containing $150 \mathrm{~mm}$-sodium chloride, $0.05 \%$ (v/v) Triton X-100 and $3.8 \mathrm{mm-}$ sodium azide) were added to medium containing spermatozoa to help prevent agglutination of spermatozoa and epithelial cells. This mixture was then diluted to a known volume with DMEM and the total number of spermatozoa was calculated using a Bright-Line haemocytometer (Reichert Scientific Instruments, Warner-Lambert Technologies Inc., New York, NY, USA).

After sperm extraction, tissue was fixed in Bouin's fluid, processed for routine light microscopy, stained and examined for the presence of spermatozoa to ensure the procedure had been successful.

Testis. Tubules of the testis were dissected free of the tunica albuginea and placed in several drops of DMEM. Spermatozoa were removed via the cut and squeeze method described above and counted as per the epididymis. Testicular sperm number was only assessed for Groups 2, 3 and 4.

\section{Results}

\section{Weight changes}

Testicular weight declined steadily throughout the study period from $0.122 \pm 0.009 \mathrm{~g}$ in late July to a minimum of $0.036 \pm 0.003 \mathrm{~g}$ in late August (Fig. 2). Epididymal weight remained relatively constant at $0.070 \pm 0.002 \mathrm{~g}$ from start of sampling in late July until mid-August when it too declined at a rate similar to that of the testis (Fig. 2).

\section{Changes in testicular and epididymal sperm number}

In early August about $0.90 \times 10^{6} \pm 0.16 \times 10^{6}$ spermatozoa/testis were present in Group 2 males, but most of these had passed out of the testis by 10 August in Group 3 animals. Very few testicular spermatozoa were found in samples taken on 24 August $\left(0.014 \times 10^{6} \pm 0.006 \times 10^{6} /\right.$ testis; Fig. 3a) from Group 2 males.

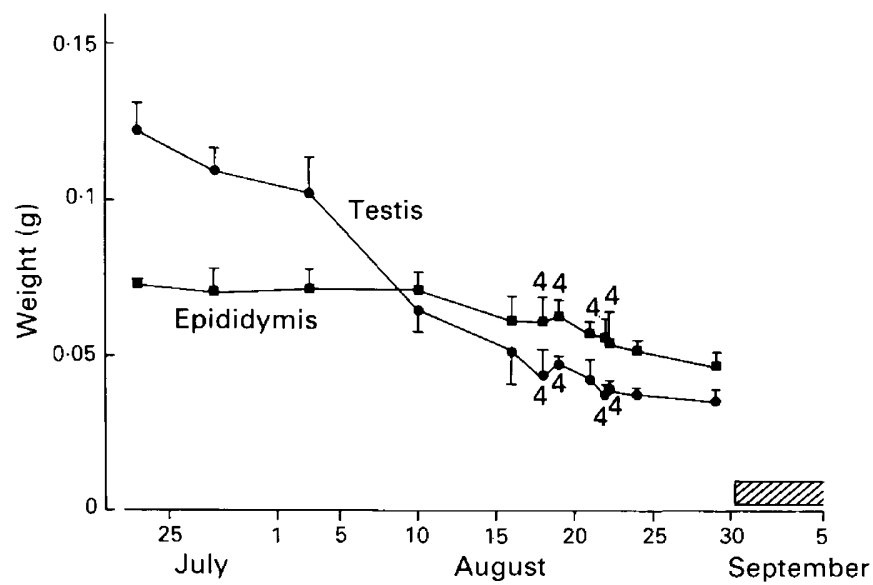

Fig. 2. Testicular and epididymal weight changes in brown marsupial mice throughout the sample period. Values are mean \pm s.d. for 5 males/group except where indicated. Hatched area $=$ male die-off.

Epididymal spermatozoa in control animals increased rapidly in number during early August, reaching a maximum of $3.50 \times 10^{6} \pm 0.58 \times 10^{6} /$ epididymis. Sperm number then declined as further recruitment from the testis diminished (Fig. 3b). Despite males in the control groups remaining unmated throughout the study period, testicular and epididymal sperm counts continued 


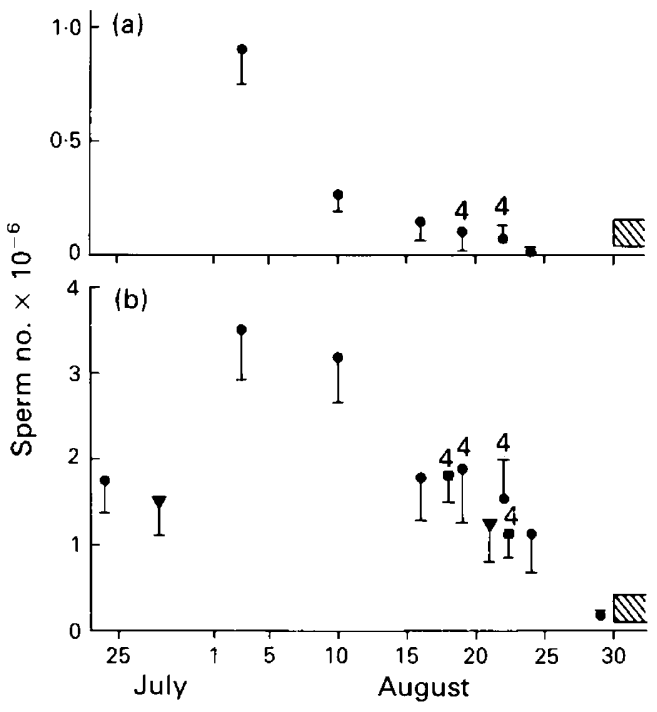

Fig. 3. Changes in total (a) testicular and (b) epididymal sperm number during the mating season in August. Values are mean \pm s.d. for 5 males/group except as indicated. $0=$ Groups $1,2,3$ and $4 ; \boldsymbol{\Delta}=$ Group $5 ; \boldsymbol{\square}=$ Group 6 . Hatched area = male die-off.

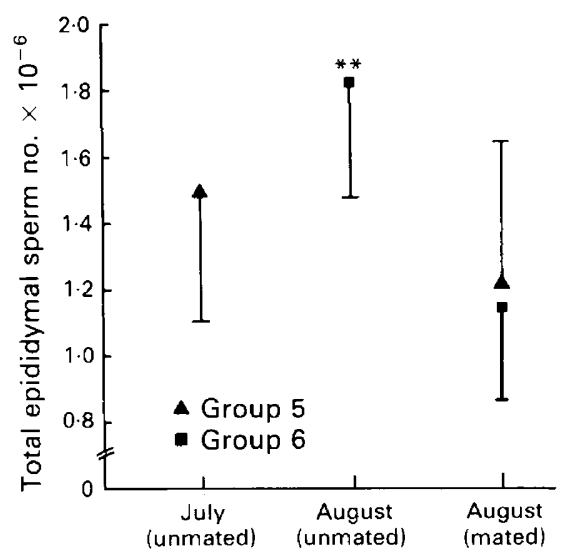

Fig. 4. Change in total epididymal sperm number in Groups 5 and 6 after 3 matings in midAugust. Values are mean \pm s.d. for 4 or 5 males/group. ${ }^{* *} P<0 \cdot 005$, compared to Group 6 mated males.

to decline. Fewer than $0.20 \times 10^{6}$ spermatozoa remained in each epididymis at the end of the mating season (late August). These spermatozoa were mostly confined to the corpus and caudal segments (Fig. 3b).

Three matings in mid-August after hemicastration reduced the mean number of spermatozoa in the remaining epididymis of Group 5 males by $\sim 0.3 \times 10^{6}$ spermatozoa/epididymis, but this did not represent a significant decline (Fig. 4).

Total epididymal sperm counts recorded between 18 and 22 August in Group 6 males after 3 successful matings were significantly different from pre-mating sperm counts $(P<0.005)$, with a loss of $\sim 0.70 \times 10^{6}$ spermatozoa/epididymis between samples (Fig. 4). Since 3 matings had occurred between hemicastration and castration an average of $0.23 \times 10^{6}$ spermatozoa was delivered per 
mating. However, this figure does not take into account the possibility of sperm loss via spermatorrhoea or self stimulation during this period, which would further reduce the total number of spermatozoa ejaculated at each mating (Figs $3 \mathrm{~b}$ and 4 ).

In unmated controls during the mating season, $\sim 2.75 \times 10^{6}$ spermatozoa were shed at an average of $0.15 \times 10^{6} /$ day/epididymis and at a relatively constant rate (Fig. 5; regression equation, $y=4.527-0.146 x ; r$ value, 0.97 ). This suggests that about $0.58 \times 10^{6}$ spermatozoa/epididymis may have been lost in the 4-day interval between hemicastration and castration in Group 6 males which was not accounted for by ejaculatory sperm losses.

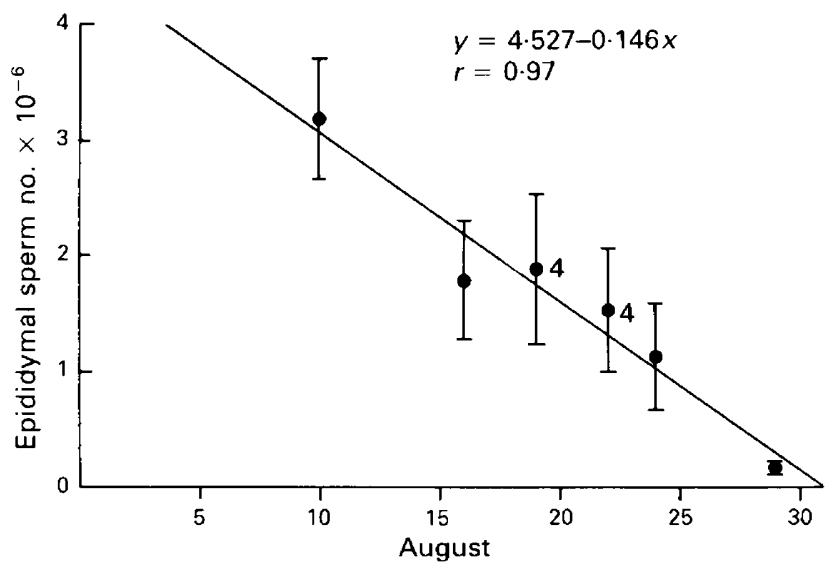

Fig. 5. Regression analysis of epididymal sperm number in brown marsupial mice in Groups 1, 2,3 and 4 (controls) during the mating season, showing the rate at which sperm loss occurs in unmated males between 10 and 29 August. Values are mean \pm s.d. for 5 males/group except as indicated.

A few small aggregates of spermatozoa were observed trapped in tubule convolutions of tissues after extrusion, but it was estimated that these represented $<5 \%$ of original sperm numbers in the tissue and hence that further assessment was not warranted.

\section{Epididymal sperm distribution}

Sperm distribution along the epididymis in late July was characterized by peaks in sperm number in both the distal caput and distal corpus/proximal cauda regions of the duct (Fig. 6). Substantially lower numbers of spermatozoa occurred in the proximal corpus and distal cauda regions of the tract at this time (Fig. 6). Epididymal sperm number increased in distal corpus/ proximal cauda segments in early August, corresponding to a sharp decline in sperm number in the testis (Figs 3b,6). Throughout August the epididymis was characterized by a single sperm peak in the distal corpus/proximal cauda segments. Caudal sperm numbers were low throughout this period (Fig. 6).

Recruitment of spermatozoa into the epididymis from the testis ceased by about mid-August, but a few residual spermatozoa $\left(<0.20 \times 10^{6}\right.$; Fig. 3a) remained apparently trapped within the testis. No spermatozoa were found in proximal caput regions of the epididymis after this time (Fig. 6). Only the most distal epididymal segments contained spermatozoa at the end of August (Figs 3a, b, 6).

Epididymal sperm distributions in Groups 5 and 6 were not significantly different from those observed in control animals recorded at a similar time during the mating season (Fig. 7). 

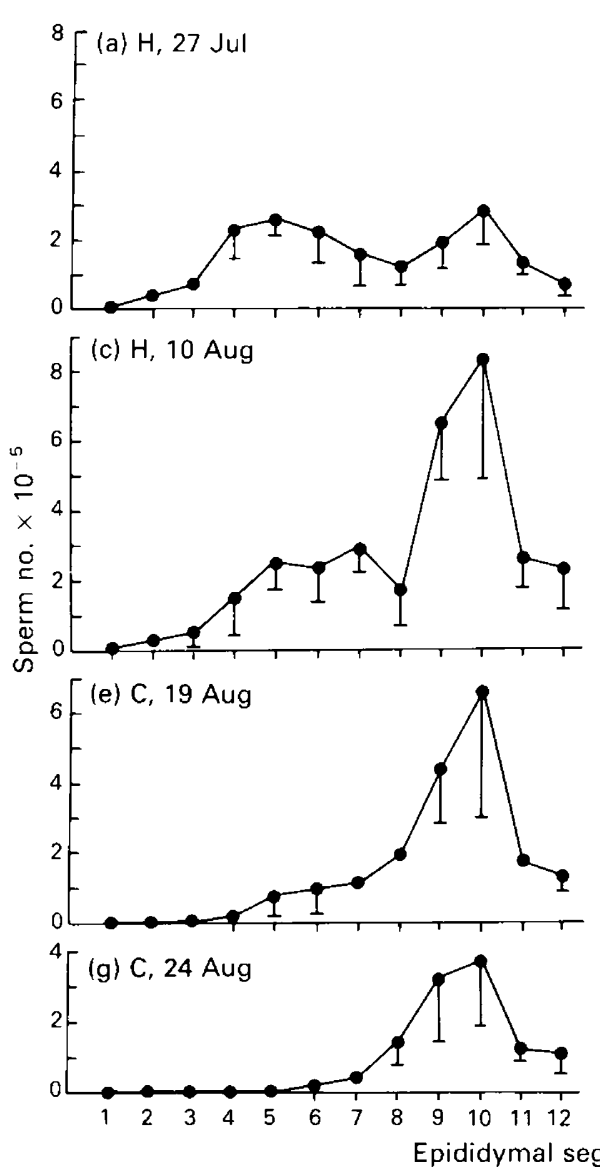

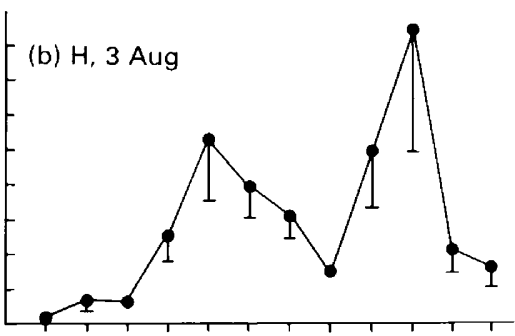

(d) H, 16 Aug

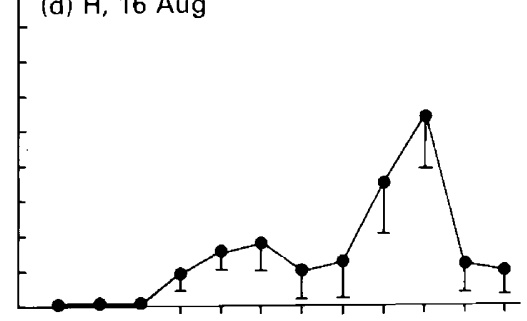

(f) C, 22 Aug

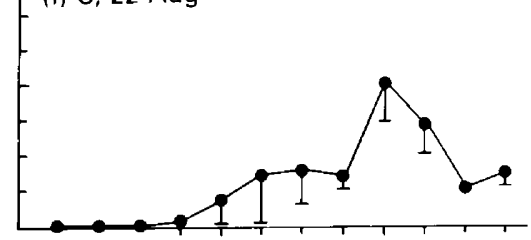

(h) C, 29 Aug

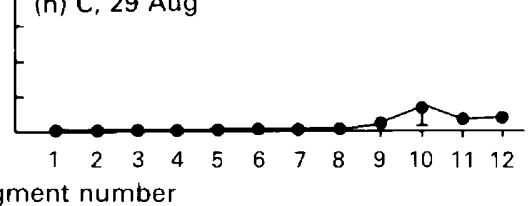

Fig. 6. Epididymal sperm distribution in males in Groups 1 (a \& h), 2 (b \& g), 3 (c \& e) and $4(\mathrm{~d} \& \mathrm{f})$ before and during the mating season, showing influx of spermatozoa in early August and decline. $\mathrm{H}=$ hemicastration; $\mathrm{C}=$ castration.

\section{Discussion}

Sperm production is restricted to a brief period in the 11-month life cycle of the brown marsupial mouse (Woolley, 1966; Kerr \& Hedger, 1983). Spermatogenic activity begins in May, mature spermatozoa are first observed in June and by early August, following a significant decline in testicular weight, the seminiferous epithelium shows complete regression to almost a Sertoli cellonly condition (Kerr \& Hedger, 1983). Few spermatozoa $\left(<0.9 \times 10^{6} /\right.$ testis) remained in the testis at the start of the mating season in early August and by mid-August these had passed into the epididymis, which was also showing a rapid decline in sperm content. Therefore at a time in the life history of the male when mating activity is drawing on the sperm reserves of the epididymis, replenishment of spermatozoa from the testis is no longer possible.

Despite the failing spermatogenic function of the testis, Kerr \& Hedger (1983) have shown that plasma androgen concentrations, which reached a peak in early July, remain high until male die-off occurs in late August, about 3 weeks after the start of mating. Testicular regression in the brown marsupial mouse therefore differs from seasonal regression seen in many other mammals (Lincoln \& Short, 1980; Lincoln, 1981) in which changes in spermatogenic and androgenic functions of the 

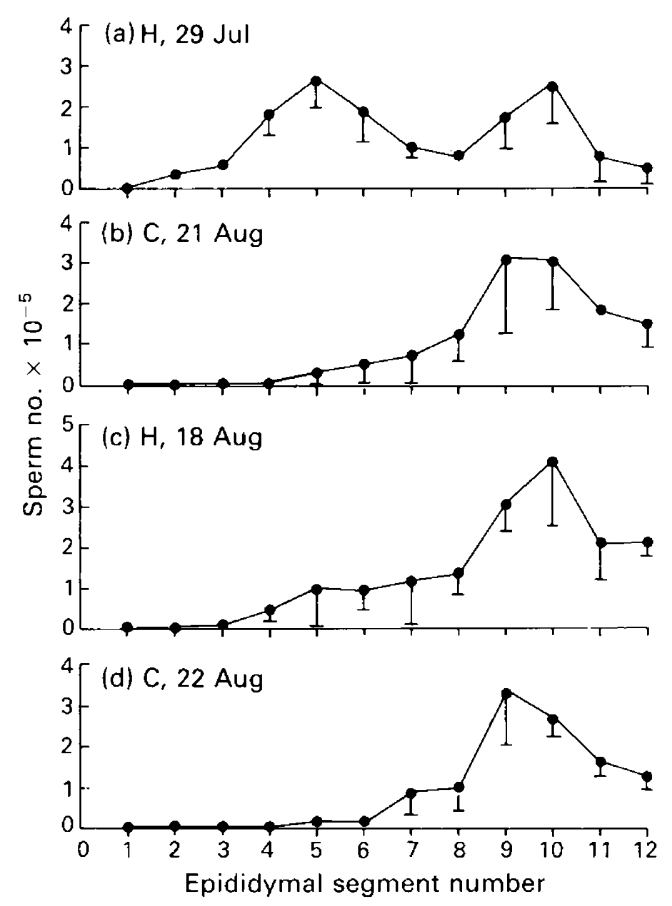

Fig. 7. Epididymal sperm distribution in males in Groups 5 (a \& b) and 6 (c \& d). H = hemicastration; $\mathrm{C}=$ castration.

testis are closely linked and usually decline together after the breeding season. Dissociation of these functions in the brown marsupial mouse testis is an important event in the life history of the male since high levels of circulating androgen are usually required to preserve maturation and viability of spermatozoa in the epididymis (Bedford, 1975, 1979) and also to maintain libido during the mating season, which occurs after testicular failure in this species. Paradoxically, in the brown marsupial mouse, these same high androgen levels are a causative factor in the die-off of males at the end of the mating season (Lee et al., 1977; Lee \& Cockburn, 1985).

In the epididymis the number and distribution of spermatozoa showed marked changes during the period of study and various factors have been identified which contribute to these changes. For example, the increasing sperm content of the epididymis during July reflected the increasing output of spermatozoa from the testis as spermatogenesis and sperm release reached a maximum. By late July approximately $1.8 \times 10^{6}$ spermatozoa were present in the epididymis of control and experimental groups. The distribution of spermatozoa at this time reflects the differences in luminal surface area calculations for various regions of the ductus epididymidis in July (Taggart \& Temple-Smith, 1989) which peaked in the distal caput and distal corpus/proximal cauda regions of the duct. Decline in the recruitment of spermatozoa from the testis after this period caused changes to the pattern of distribution of spermatozoa in the epididymis. In particular there was a decline in spermatozoa from the distal caput region which appeared to sustain the concentration of spermatozoa in the distal corpus/proximal cauda epididymidis until late in the mating season. Despite diminishing sperm reserves in the testis and upper regions of the epididymis, sperm number in the caudal region of the duct remained remarkably constant at approximately $0.32 \times 10^{6} \pm 0.09 \times 10^{6}$ spermatozoa/side.

In early August, the total number of spermatozoa available for the duration of the mating season is the sum of those remaining in the testis $\left(0.9 \times 10^{6} /\right.$ testis $)$ and the epididymis $\left(3.5 \times 10^{6}\right.$ epididymis), i.e. $\sim 4.4 \times 10^{6}$ spermatozoa/side. The number of epididymal spermatozoa remains relatively high until mid-August which corresponds closely to the period of oestrus and mating 
activity in populations of brown marsupial mice in south-eastern Victoria (Lee et al., 1977; Scott \& Tan, 1985; Selwood, 1987). Clearly a close synchronization between reproductive events in the remale (Selwood, 1985) and the male (Woolley, 1966; Kerr \& Hedger, 1983; this study) is needed to ensure that successful insemination of oestrous females is achieved before either sperm reserves are exhausted or the males die-off (Wood, 1970; Lee et al., 1977, 1982).

Spermatorrhoea is another important factor which needs to be considered in relation to changes in the number and distribution of epididymal spermatozoa, in brown marsupial mice, especially in the period after spermatogenic failure. Spermatorrhoea was first reported in the brush-tailed possum (Bolliger \& Carrodus, 1938) and has since been found to occur in all sexually active male marsupials which have been examined, including $A$. stuartii (Woolley, 1966), which shows sperm loss in the urine from June until male die-off. The daily loss of $\sim 0.146 \times 10^{6}$ spermatozoa/epididymis estimated for the control groups during the mating season in this study results in very few spermatozoa remaining in the reproductive tract at die-off $\left(<0.2 \times 10^{6}\right.$ spermatozoa/epididymis $)$ even in unmated males.

During August, therefore, when the epididymal sperm reserves are dwindling under the combined effects of mating activity and testicular failure, the potential fertility of males is being further reduced, especially later in the breeding season, by the unrelenting effects of spermatorrhoea. Reduced sperm concentrations in the epididymis at this time may explain the lower litter success rates of females mated late in the breeding season (Selwood, 1987). The similarities seen in number and distribution of epididymal spermatozoa between control and mated groups of males in this study do not diminish the effects of mating or spermatorrhoea on epididymal sperm reserves but suggest the possibility, for which there is currently no supporting evidence available, that each mating may briefly change the dynamics of sperm loss by spermatorrhoea.

The effects in brown marsupial mice of reduced caudal storage and mating on epididymal sperm reserves deserve some further comment. Unusually low numbers of spermatozoa in the cauda epididymidis of some didelphid and dasyurid marsupials led Bedford et al. (1984) to the conclusion that few spermatozoa would be present in the ejaculate. From our study it was possible to estimate the number of spermatozoa delivered at each mating by male brown marsupial mice. Both upper and lower limits $\left(0.23 \times 10^{6}\right.$ and $0.039 \times 10^{6}$ spermatozoa/epididymis/mating) were determined with the upper limit referring to all spermatozoa lost per epididymis/mating after 3 consecutive matings and the lower limit to those lost from each epididymis/mating after the sperm loss calculated for spermatorrhoea had been taken into account. How many matings therefore could the cauda epididymidis sustain if we exclude replenishment of spermatozoa from more proximal regions of the epididymis? Since the cauda epididymidis contains approximately $0.32 \times 10^{6}$ spermatozoa and assuming that male Antechinus deliver $0.23 \times 10^{6}$ spermatozoa/epididymis/mating (the upper limit) then at worst caudal spermatozoa would be exhausted in 1.5 matings and at best, if we assume that $\sim 0.039 \times 10^{6}$ spermatozoa (the lower limit) are delivered per epididymis/mating, reserves of spermatozoa would last for approximately 9 matings. The actual number probably lies between these two estimates and to evaluate it more precisely the effect of mating on levels of spermatorrhoea would need to be determined.

As suggested from previous studies (Bedford et al., 1984; Taggart \& Temple-Smith, 1989), estimates of the number of spermatozoa in ejaculates of didelphid and dasyurid marsupials are significantly lower than those in ejaculates of eutherian mammals of equivalent size (e.g., mouse: $50 \times 10^{6}$; rat: $58 \times 10^{6}$; rabbit: $200-500 \times 10^{6}$ ) and also for other marsupials (Moore \& Bedford, 1978; Amann, 1981; Bedford et al., 1984; Southwick \& Temple-Smith, 1988). In these mammals the number of spermatozoa stored in the cauda epididymidis generally accounts for more than $50 \%$ of the total epididymal spermatozoa (Amann, 1981), and tubule and luminal diameters are greatest and epithelial height is lowest in this region to facilitate sperm storage (Hamilton, 1975; Jones et al., 1984; Cummins et al., 1986; Robaire \& Hermo, 1988). Our study of epididymal structure in the brown marsupial mouse has provided an explanation for its low caudal sperm storage capacity (approximately $39 \%$ of the total epididymal spermatozoa are situated in the cauda, with about 
$17 \%$ located in the distal caudal segments) (Taggart \& Temple-Smith, 1989). The shape of the lumen changes from circular in the caput and corpus regions to a narrower and slit-like structure in the distal cauda epididymidis which is lined by a tall epithelium. This shape change appears to result in a reduced sperm storage capacity in the cauda rather than the expanding capacity which characterizes many other marsupials and most eutherian mammals. From observations made in this and our previous study on epididymal structure in brown marsupial mice (Taggart \& Temple-Smith, 1989), the major peak of sperm concentration appears to be in the distal corpus and proximal cauda regions of the epididymis. This suggests that the unusual caudal structure and reduced storage capacity in this region of the epididymis may function to limit the number of spermatozoa available for ejaculation and thereby act as a mechanism for conserving the dwindling sperm reserves of the epididymis, especially during the mating season. If so this would help to maximize the number of successful matings for each male during the breeding season and ensure that the reproductive potential of the most successful males was not diminished by frequent mating.

The possibility that sperma tozoa in the vas deferens may contribute significantly to the ejaculate in this species was disregarded after assessment of the number of spermatozoa occupying the proximal $2 \mathrm{~cm}$ of the vas deferens immediately distal to the cauda epididymidis (unpublished observations): relatively few spermatozoa occupy this region throughout the breeding season $\left(0.0022 \times 10^{6} \pm\right.$ $0.0020 \times 10^{6}$ spermatozoa side, $n=20$ ). Assuming our figures mirror sperm distribution throughout the vas deferens, which is about $5 \mathrm{~cm}$ in length with no distal specializations for sperm storage, the presence of large numbers of spermatozoa in the vas deferens which could significantly contribute to the spermatozoa content of the ejaculate seems improbable.

The reproductive biology of the male brown marsupial mouse is an interesting component in the unusual life history of this species (Lee et al., 1977). The balance between the effects of testicular failure, spermatorrhoea and polygynous mating activity on sperm reserves in the epididymis and the need to mate successfully before male die-off occurs is maintained for the most part by the close synchronization of male and female reproductive cycles. Restricted release of spermatozoa from the epididymis coupled with the presence of storage crypts in the oviduct which protect sperm viability in the female tract for periods in excess of 1 week before ovulation occurs (Selwood, 1982, 1987) may enable Antechinus stuartii, with its finite number of spermatozoa, to inseminate small quantities of spermatozoa with remarkable success. Perhaps these reproductive strategies have evolved together to maximize the reproductive potential of individual males in this polygynous species with limited epididymal sperm reserves during the breeding season.

We thank Jo Hamer and Julie Hoy for excellent technical assistance; Jenny McKervey and Lloyd Ellis for photographic assistance; Sue Simpson for help with preparation of diagrams and the Victorian Department of Conservation, Forests and Lands for approval to conduct this investigation.

\section{References}

Amann, R.P. (1981) A critical review of methods for evaluation of spermatogenesis from seminal characteristics. $J$. Androl. 2, 37-58.

Amann, R.P., Thompson, D.L., Squires, E.L. \& Pickett, B.W. (1979) Effects of age and frequency of ejaculation on sperm production and extragonadal reserves in stallions. J. Reprod. Fert., Suppl. 27, 1-6.

Bedford, J.M. (1975) Maturation, transport and fate of spermatozoa in the epididymis. In Handbook of Physiology: Endocrinology, Section 7, Vol. V, pp. 303-317. Eds D. W. Hamilton \& R. O. Greep. Am. Physiol. Soc., Washington DC.

Bedford, J.M. (1978) Anatomical evidence for the epididymis as the prime mover in the evolution of the scrotum. Am. J. Anat. 152, 483-508.
Bedford, J.M. (1979) Evolution of the sperm maturation and sperm storage functions of the epididymis. In The Spermatozoon, pp. 7-22. Eds D. W. Fawcett \& J. M. Bedford. Urban and Schwarzenberg, Baltimore.

Bedford, J.M., Rodger, J.C. \& Breed, W.G. (1984) Why so many mammalian spermatozoa-a clue from marsupials? Proc. R. Soc. B. 221, 221-233.

Bolliger, A. \& Carrodus, A.L. (1938) Spermatorrhoea in Trichosurus vulpecula and other marsupials. Med. $J$. Aust. 2, $1118-1119$.

Bradley, A.J., McDonald, I.R. \& Lee, A.K. (1980) Stress and mortality in a small marsupial (Antechinus stuartii, Macleay). Gen. comp. Endocrinol. 40, 188-200.

Cummins, J.M. (1981) Sperm maturation in the possum Trichosurus vulpecula: a model for comparison with 
eutherian mammals. In Marsupials in New Zealand, 74, pp. 23-39. Ed. B. D. Bell. Zoology Publications, Victoria University of Wellington, New Zealand.

Cummins, J.M., Temple-Smith, P.D. \& Renfree, M.B. (1986) Reproduction in the male honey possum (Tarsipes rostratus: Marsupialia): the epididymis. Am. J. Anat. 177, 385-402.

Glover, T.D. \& Nicander, L. (1971) Some aspects of structure and function in the mammalian epididymis. J. Reprod. Fert., Suppl. 13, 39-50.

Godfrey, G.K. (1969) Infiuence of increased photoperiod on reproduction in the dasyurid marsupial, Sminthopsis crassicaudata. J. Mammal. 50, 132-133.

Hamilton, D.W. (1975) Structure and function of the epithelium lining the ductuli efferentes, ductus epididymidis and ductus deferens in the rat. In Handbook of Physiology, section 7, vol. 5, pp. 259-301. Eds R. O. Greep \& E. B. Astwood. Am. Physiol. Soc., Washington DC.

Jones, R.C., Hinds, L.A. \& Tyndale-Biscoe, C.H. (1984) Ultrastructure of the epididymis of the tammar, Macropus eugenii, and its relation to sperm maturation. Cell Tiss. Res. 237, 525-535.

Kerr, J.B. \& Hedger, M.P. (1983) Spontaneous spermatogenic failure in the marsupial mouse Antechinus stuartii, Macleay (Dasyuridae: Marsupialia). Aust. J. Zool. 31, 445-466.

Lazenby-Cohen, K.A. \& Cockburn, A. (1988) Lek promiscuity in a semelparous mammal, Antechinus stuartii (Marsupialia: Dasyuridae)? Behav. Ecol. Sociobiol. 22, 195-202.

Lee, A.K. \& Cockburn, A. (1985) Evolutionary Ecology of Marsupials (Monographs on Marsupial Biology). Cambridge University Press, Cambridge.

Lee, A.K., Bradley, A.J. \& Braithwaite, R.W. (1977) Corticosteroid levels and male mortality in Antechinus stuartii. In The Biology of Marsupials, pp. 209-220. Eds B. Stonehouse \& D. Gilmore. Macmillan, London.

Lee, A.K., Woolley, P. \& Braithwaite, R.W. (1982) Life history strategies of dasyurid marsupials. In Carnivorous Marsupials, vol. 1, pp. 1-11. Ed. M. Archer. Royal Zoological Society of NSW, Sydney.

Lincoln, G.A. (1981) Seasonal aspects of testicular function. In The Testis, ch. 12, pp. 255-302. Eds H. Burger \& D. M. de Kretser. Raven Press, New York.
Lincoln, G.A. \& Short, R.V. (1980) Seasonal breeding: Natures contraceptive. Recent Prog. Horm. Res. 36, $1-52$.

Moore, H.D. \& Bedford, J.M. (1978) Fate of spermatozoa in the male. 1. Quantitation of sperm accumulation after vasectomy in the rabbit. Biol. Reprod. 18, 784-790.

Robaire, B. \& Hermo, L. (1988) Efferent ducts, epididymis and vas deferens: structure, functions and their regulation. In The Physiology of Reproduction, vol. 2, pp. 999-1080. Eds E. Knobil \& J. D. Neill. Raven Press, New York

Scott, M.P. \& Tan, T.N. (1985) A radiotracer technique for the determination of male mating success in natural populations. Behav. Ecol. Sociobiol. 17, 29-33.

Selwood, L. (1982) A review of maturation and fertilization in marsupials with special reference to the dasyurids: Antechinus stuartii. In Carnivorous Marsupials, vol. 1, pp. 65-76. Ed. M. Archer. Royal Zoological Society of NSW, Sydney.

Selwood, L. (1985) Synchronisation of oestrus, ovulation and birth in female Antechinus stuartii (Marsupialia: Dasyuridae). Aust. Mammal. 8, 91-96.

Selwood, L. (1987) Relationship between longevity of spermatozoa after insemination and the percentage of normal embryos in brown marsupial mice (Antechinus stuartii). J. Reprod. Fert. 79, 495-503.

Southwick, G.J. \& Temple-Smith, P.D. (1988) Epididymal microsurgery: current techniques and new horizons. Microsurgery 9, 266-277.

Taggart, D.A. \& Temple-Smith, P.D. (1989) Structural features of the epididymis in a Dasyurid marsupial (Antechinus stuartii). Cell. Tiss. Res. 258, 203-210.

Taylor, J.M. \& Horner, B.E. (1970) Gonadal activity in the marsupial mouse, Antechinus bellus with notes on other species of the genus (Marsupialia: Dasyuridae). J. Mammal. 51, 659-668

Temple-Smith, P.D. \& Bedford, J.M. (1976) The features of sperm maturation in the epididymis of a marsupial, the brush tailed possum Trichosurus vulpecula. Am.J. Anat. 147, 471-500.

Wood, D.H. (1970) An ecological study of Antechinus stuartii (Marsupialia) in a south east Queensland rainforest. Aust. J. Zool. 18, 185-207.

Woolley, P. (1966) Reproduction in Antechinus spp. and other Dasyurid marsupials. Symp. zool. Soc. Lond. 15, $28 \mathrm{I}-294$

Received 21 February 1989 